\title{
Anaplastic Brain Stem Glioma
}

National Cancer Institute

\section{Source}

National Cancer Institute. Anaplastic Brain Stem Glioma. NCI Thesaurus. Code C7446.

An anaplastic glioma that arises from the brain stem. 